\title{
Antitumor efficacy of a novel CLA-PTX microemulsion against brain tumors: in vitro and in vivo findings
}

This article was published in the following Dove Press journal:

International Journal of Nanomedicine

14 December 2012

Number of times this article has been viewed

Dan Li'
Ke Yang'
Jie-Si Li'
Xi-Yu Ke'
Yu Duan'
Ruo Du'
Ping Song'
Ke-Fu Yu'
Wei Ren'
Dan Huang'
Xing-Huo Li'
Xin Hu'
Xuan Zhang'
Qiang Zhang ',2
'Department of Pharmaceutics,
'State Key Laboratory of Natural
and Biomimetic Drugs, School of
Pharmaceutical Sciences, Peking
University, Beijing, China

Correspondence: Xuan Zhang

Department of Pharmaceutics, School of Pharmaceutical Sciences, Peking University, Xueyuan Road 38, Beijing I00191, China

Tel +861082802683

Fax +861082802683

Email xuanzhang@bjmu.edu.cn

\begin{abstract}
Background: Considering the observations that linoleic acid conjugated with paclitaxel (CLA-PTX) possesses antitumor activity against brain tumors, is able to cross the blood-brain barrier, but has poor water solubility, the purpose of this study was to prepare a novel CLA-PTX microemulsion and evaluate its activity against brain tumors in vitro and in vivo.

Methods: The in vitro cytotoxicity of a CLA-PTX microemulsion was investigated in C6 glioma cells. The in vivo antitumor activity of the CLA-PTX microemulsion was evaluated in tumorbearing nude mice and rats. The pharmacokinetics of the CLA-PTX microemulsion were investigated in rats, and its safety was also evaluated in mice.

Results: The average droplet size of the CLA-PTX microemulsion was approximately $176.3 \pm 0.8 \mathrm{~nm}$ and the polydispersity index was $0.294 \pm 0.024$. In vitro cytotoxicity results showed that the $\mathrm{IC}_{50}$ of the CLA-PTX microemulsion was $1.61 \pm 0.83 \mu \mathrm{M}$ for a C6 glioma cell line, which was similar to that of free paclitaxel and CLA-PTX solution $(P>0.05)$. The antitumor activity of the CLA-PTX microemulsion against brain tumors was confirmed in our in vivo C6 glioma tumor-bearing nude mice as well as in a rat model. In contrast, Taxol ${ }^{\circledR}$ had almost no significant antitumor effect in $\mathrm{C} 6$ glioma tumor-bearing rats, but could markedly inhibit growth of C6 tumors in C6 glioma tumor-bearing nude mice. The pharmacokinetic results indicated that CLA-PTX in solution has a much longer circulation time and produces higher drug plasma concentrations compared with the CLA-PTX microemulsion. The results of the acute toxicity study showed that the $\mathrm{LD}_{50}$ of CLA-PTX solution was $103.9 \mathrm{mg} / \mathrm{kg}$. In contrast, the CLA-PTX microemulsion was well tolerated in mice when administered at doses up to $200 \mathrm{mg} / \mathrm{kg}$.
\end{abstract}

Conclusion: CLA-PTX microemulsion is a novel formulation with significant antitumor efficacy in the treatment of brain tumors, and is safer than CLA-PTX solution.

Keywords: CLA-PTX, microemulsion, pharmacokinetics, brain tumor, antitumor efficacy, safety

\section{Introduction}

Conjugated linoleic acids are a structurally unique group of dietary long chain polyunsaturated fatty acids which have aroused considerable interest because of their significant antiproliferative effects on cancer cells in vitro and antitumor effects in animal models in vivo. ${ }^{1-6}$ The synergistic antitumor activity of taxane agents incorporated with linoleic acid has been confirmed. ${ }^{7,8}$ Conjugation of linoleic acid with paclitaxel (CLA-PTX) has been previously reported by our laboratory. ${ }^{9}$ The targeting effect of CLA-PTX on C6 glioma cells was demonstrated by in vitro cellular uptake experiments. The results showed that the extent of CLA-PTX uptake in C6 glioma cells was much greater than that of paclitaxel. Biodistribution results revealed that 
CLA-PTX, unlike paclitaxel, could distribute in brain tissue and remain there for a long time, indicating that CLA-PTX could cross the blood-brain barrier, reaching the brain and targeting brain tumors where it exerts a therapeutic effect. Unfortunately, the solubility of CLA-PTX was very low. In our previous research, the solvent used in the CLA-PTX formulation for intravenous administration was the same as that used for the paclitaxel injection $\left(\right.$ Taxol $^{\circledR}$, a mixture of Cremophor ${ }^{\circledR}$ EL [polyethoxylated castor oil, CrEL] and ethanol [1:1, v/v], Bristol Myers Squibb Co, Princeton, NJ). ${ }^{9}$ Therefore, development of a novel formulation of CLA-PTX would be of great value.

It is well known that current strategies for increasing the solubility of poorly water-soluble drugs involve cosolvency, emulsification, microemulsification, drug complexation with cyclodextrins, and carrier mediation using liposomes or nanoparticles. ${ }^{10-12} \mathrm{~A}$ microemulsion is an isotropic, thermodynamically stable, transparent (or translucent) system consisting of oil, water, and a surfactant, frequently in combination with a cosurfactant, and a droplet size usually in the range of $20-200 \mathrm{~nm} .{ }^{13-16}$ The major advantages of microemulsions are their high solubilization potential, thermodynamic stability, ability to improve the dissolution of lipophilic drugs, and surfactant-induced permeability enhancement. ${ }^{17}$ The obvious benefits of microemulsions as drug delivery systems have led to the development of several systems for intravenous administration. Recently, a novel paclitaxel microemulsion was developed for intravenous administration in our laboratory. ${ }^{18}$ In addition, considering that conjugated linoleic acid is a mixture of positional and geometric isomers of octadecadienoic acid, which is a component of some conjugated linoleic acid-rich soy oils, we hypothesized that the solubility of conjugated linoleic acid in oil would be high. We believed that the compatibility of CLA-PTX in oil, like conjugated linoleic acid, would be acceptable, and that development of a CLA-PTX microemulsion would be very feasible.
The present study describes the preparation of a CLA-PTX microemulsion and its characterization. The cytotoxicity of the CLA-PTX microemulsion in C6 glioma cells was assessed in vitro. The in vivo antitumor activity of the CLA-PTX microemulsion was evaluated in tumor-bearing nude mice and tumor-bearing rats, and its pharmacokinetics were investigated in rats. The acute toxicity of the CLA-PTX microemulsion was also evaluated in imprinting control region (ICR) mice.

\section{Materials and methods Chemicals and animals}

CLA-PTX was synthesized from conjugated linoleic acid and paclitaxel using the method described in a previous article published by our laboratory. ${ }^{9}$ The structure and molecular weight of CLA-PTX are shown in Figure 1. CrEL of higher purity was purchased from BASF Corporation (Shanghai, China). Egg phosphatidylcholine (Lipoid E 80) was obtained from Lipoid GmbH (Shanghai Toshisun Enterprise Co, Ltd, Shanghai, China). Paclitaxel was obtained from MeiLian Co, Ltd (Chongqing, China). Taxol ${ }^{\circledR}$ for injection was supplied by a local Beijing hospital, and contained $30 \mathrm{mg}$ of paclitaxel in $5 \mathrm{~mL}$ of $50 \% \mathrm{CrEL}(\mathrm{v} / \mathrm{v})$ and $50 \%$ dehydrated ethanol (v/v). F10 cell culture medium, penicillin-streptomycin, fetal bovine serum, and donor equine serum were sourced from Gibco Invitrogen Co (Carlsbad, CA). All other reagents were of analytical or high-performance liquid chromatography grade.

Sprague-Dawley rats weighing $200 \pm 20 \mathrm{~g}$, ICR mice weighing 20-22 g (aged 3-4 weeks), and female Balb/c nude mice weighing 18-22 g (aged 5-6 weeks) were obtained from the Experimental Animal Center of Peking University Health Science Center. All care and handling of the animals were performed in accordance with the requirements of the Institutional Authority for Laboratory Animal Care of Peking University.

\section{Cell culture}

Murine C6 glioma cells (Institute of Material Medical, Chinese Academy of Medical Sciences and Peking Union

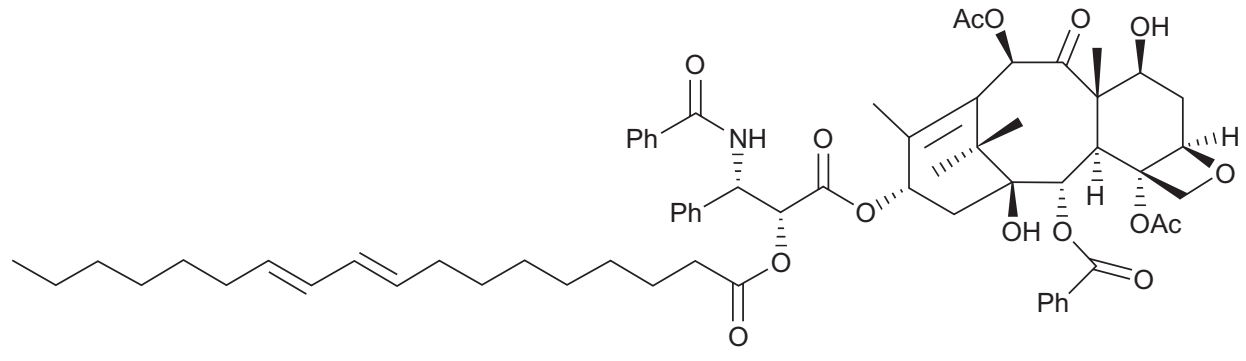

Figure I Structure, molecular formula, and molecular weight of CLA-PTX.

Notes: Molecular formula of CLA-PTX $\mathrm{C}_{65} \mathrm{H}_{81} \mathrm{NO}_{15}$. Molecular weight of CLA-PTX 1116.

Abbreviation: CLA-PTX, linoleic acid conjugated with paclitaxel. 
Medical College, Beijing, China) were used and maintained in Ham's F10 medium supplemented with $2.5 \%$ fetal bovine serum, $15 \%$ donor equine serum, and $1 \%$ penicillinstreptomycin solution. The cells were incubated at $37^{\circ} \mathrm{C}$ in a humidified environment of $5 \% \mathrm{CO}_{2}$.

\section{Preparation of CLA-PTX microemulsion}

The CLA-PTX microemulsion was prepared in our laboratory with some modification of the published method. ${ }^{18}$ In brief, to prepare a concentrated CLA-PTX microemulsion, CLAPTX was dissolved in dehydrated alcohol and then mixed with Lipoid E 80, CrEL, and soybean oil. The concentration of CLA-PTX in the microemulsion was $80 \mathrm{mg} / \mathrm{mL}$. When this concentrated solution was mixed with a $5 \%$ glucose infusion, it underwent self-emulsification to form a CLAPTX microemulsion (an oil/water microemulsion with a final CLA-PTX concentration of $2 \mathrm{mg} / \mathrm{mL}$ ). For preparation of the CLA-PTX solution, CLA-PTX was dissolved in a mixture of CrEL and ethanol $(1: 1, v / v)$. The concentration of CLA-PTX in the CLA-PTX solution was $15 \mathrm{mg} / \mathrm{mL}$.

\section{Physicochemical characterization of CLA-PTX microemulsion}

The volume of $5 \%$ glucose solution used for diluting the concentrated CLA-PTX microemulsion was $39 \mathrm{~mL}$, and the final concentration of CLA-PTX in the microemulsion was $2 \mathrm{mg} / \mathrm{mL}$. For droplet size analysis, this microemulsion was further diluted with $5 \%$ glucose solution to give a CLA-PTX concentration of about $0.8 \mathrm{mg} / \mathrm{mL}$. The droplet size in the CLA-PTX microemulsion was measured using a Malvern Zetasizer (Nano-ZS, Malvern, Worcestershire, UK) at $25^{\circ} \mathrm{C}$. Morphological examination of the CLAPTX microemulsion was performed using a transmission electron microscope (TEM) at an acceleration voltage of $200 \mathrm{kV}$ (JEM-200C, JEOL, Tokyo, Japan). Briefly, the TEM samples were prepared by dripping one drop of CAL-PTX microemulsion onto a 300-mesh Formvar-coated copper grid. The grids were negatively stained at room temperature with freshly prepared and sterile-filtered $2 \%(\mathrm{w} / \mathrm{v})$ aqueous uranyl acetate solution. The grids were then washed twice and air-dried prior to imaging.

\section{In vitro cytotoxicity}

C6 glioma cells were seeded at a density of $5 \times 10^{3}$ cells/ well in 96-well transparent plates and incubated for 24 hours. The medium was then changed and various concentrations of the CLA-PTX microemulsion were used. At 48 hours, cell viability was determined using the sulforhodamine B assay.
Briefly, the medium was removed, the cells were fixed with trichloroacetic acid, and then washed and stained with sulforhodamine B. Absorbance was measured at $540 \mathrm{~nm}$ using a 96-well plate reader (Bio-Rad 680, Bio-Rad, Hercules, CA). The survival percentages were calculated using the following formula:

$$
\begin{aligned}
\text { Survival \% } \%= & \left(\mathrm{A}_{540} \mathrm{~nm} \text { for treated cells } /\right. \\
& \left.\mathrm{A}_{540} \mathrm{~nm} \text { for control cells }\right) \times 100 \%
\end{aligned}
$$

where $\mathrm{A}_{540} \mathrm{~nm}$ is the absorbance value. Each assay was carried out in triplicate. Finally, dose-effect curves were constructed and $\mathrm{IC}_{50}$ values were calculated.

\section{In vivo antitumor efficacy}

The female Balb/c nude mice were inoculated subcutaneously in the right flank with $0.2 \mathrm{~mL}$ of a suspension of C6 glioma cells $\left(1 \times 10^{6}\right)$. When the tumor volume reached approximately $150 \mathrm{~mm}^{3}$ at about 7 days after inoculation, the mice were randomly divided into three groups, ie, a control group, a Taxol treatment group, and a CLA-PTX microemulsion treatment group. Each group consisted of six tumor-bearing mice. In this antitumor activity experiment, Taxol or the concentrated CLA-PTX microemulsion was diluted with $5 \%$ glucose infusion to give a concentration of $1.5 \mathrm{mg} / \mathrm{mL}$ or $2.0 \mathrm{mg} / \mathrm{mL}$. The groups were treated with a $5 \%$ glucose infusion (control), Taxol (15 mg/kg intravenously once every 3 days for three doses), or CLA-PTX microemulsion (20 mg/kg [equimolar with $15 \mathrm{mg} / \mathrm{kg}$ of paclitaxel] intravenously once every 3 days for three doses). Formulations were given intravenously via the tail vein. Throughout the study, the mice were weighed, their tumors were measured with calipers every 2 days, and the tumor volume was calculated as $\left[\right.$ length $\left.\times(\text { width })^{2}\right] / 2$. On day 21 post-tumor inoculation, the animals were sacrificed and tumors were harvested and weighed.

In a separate study, to establish a model of brain tumorbearing rats, murine $\mathrm{C} 6$ glioma cells were inoculated into the brains of rats using a stereotaxic instrument (RWD Life Science Co, Ltd, Shenzhen, China). A sagittal incision was made through the skin to expose the cranium. Approximately $1 \times 10^{6}$ cells per $10 \mu \mathrm{L}$ were stereotaxically implanted into the right forebrain of each rat using the following coordinates: $1.0 \mathrm{~mm}$ anterior and $3.0 \mathrm{~mm}$ lateral to bregma, at a depth of $5.0 \mathrm{~mm}$ from the brain surface. ${ }^{19}$ Animals dying from complications associated with the anesthetic procedure (ie, death within 3 hours of surgery) were excluded from further analysis. The brain tumor-bearing rats were randomly 
divided into three groups, each containing ten animals. Animals in group 1, a blank control group, were given a 5\% glucose infusion, animals in group 2 were treated with Taxol at a dose of $5 \mathrm{mg} / \mathrm{kg}$, while animals in group 3 received the CLA-PTX microemulsion at a dose of $6.67 \mathrm{mg} / \mathrm{kg}$ (equimolar with $5 \mathrm{mg} / \mathrm{kg}$ of paclitaxel). Formulations were administered via the tail vein at days 7, 10, and 13 after tumor inoculation, and the animals were sacrificed on day 20 post-tumor inoculation. The tumors were harvested and weighed. Tumor weight inhibition (TWI) was calculated using the formula:

$$
\mathrm{TWI}=[\mathrm{WC}-\mathrm{WD}] / \mathrm{WC}
$$

where WC and WD represent the tumor weight of the animals from the glucose infusion and treatment groups, respectively. $^{20}$

\section{Pharmacokinetic studies}

The CLA-PTX solution and concentrated CLA-PTX microemulsion were each diluted with $5 \%$ glucose infusion to give a final CLA-PTX concentration of $2 \mathrm{mg} / \mathrm{mL}$. Ten male Sprague-Dawley rats were randomly assigned to two groups, containing five rats each. Group 1 received an intravenous injection of CLA-PTX solution at a dose of $6.67 \mathrm{mg} / \mathrm{kg}$, while group 2 received an intravenous injection of CLA-PTX microemulsion at a dose of $6.67 \mathrm{mg} / \mathrm{kg}$, respectively. After intravenous administration, blood samples of approximately $0.5 \mathrm{~mL}$ were collected into heparinized tubes from the orbit venous plexus of each rat at different times. Plasma samples were harvested by immediate centrifugation at $3000 \mathrm{~g}$ for 5 minutes and stored at $-20^{\circ} \mathrm{C}$ until required for analysis by high-performance liquid chromatography.

Pharmacokinetic parameters were calculated from the CLA-PTX concentration-time data using noncompartmental methods and NONMEM version 7.2 (Icon Development Solutions, Ellicott City, MD). The $\mathrm{C}_{0.5}$ was the observed concentration at 0.5 hours. The area under the curve (AUC) was calculated using the linear trapezoidal method and was extrapolated to infinity $\left(\mathrm{AUC}_{\text {inf }}\right)$ by dividing the last measured concentration by the terminal rate constant, $\lambda z$, which was determined from the slope of the terminal phase of the plasma concentration-time curve. The terminal half-life $\left(t_{1 / 2}\right)$ was calculated as 0.693 divided by $\lambda z$.

\section{Acute toxicity}

The method for evaluating the acute toxicity of the CLA-PTX microemulsion was modified from a previous report. ${ }^{21}$ ICR mice were randomly divided into ten groups (five groups for treatment with the CLA-PTX solution and another five groups for treatment with the CLA-PTX microemulsion), containing ten mice each. All animals were fasted for 12 hours before intravenous administration of the study formulations. The doses used in the group receiving the CLA-PTX solution were $67,80,95.2,113.4$, and $135 \mathrm{mg} / \mathrm{kg}$, respectively. Mice in the group receiving the CLA-PTX microemulsion were given doses of 80, 95.2, 113.4, 135, 160.7, and $200 \mathrm{mg} / \mathrm{kg}$. The CLA-PTX formulations were dissolved in 5\% glucose solution for injection and administered as individual doses via the intravenous route. All groups of mice were observed for one week, and the number of mice surviving was recorded. The $\mathrm{LD}_{50}$ was calculated using the Bliss method.

\section{High-performance liquid chromatography analysis of CLA-PTX}

CLA-PTX plasma samples were extracted using our previously reported method. ${ }^{9}$ Briefly, $100 \mu \mathrm{L}$ of plasma was mixed with $2.5 \mathrm{~mL}$ acetonitrile in a vortex mixer for 30 seconds. The mixture was centrifuged at $3000 \mathrm{~g}$ for 10 minutes. Next, $2.0 \mathrm{~mL}$ of supernatant was collected and dried under a gentle stream of nitrogen gas at $50^{\circ} \mathrm{C}$ in a water bath. The residue was dissolved in $100 \mu \mathrm{L}$ of mobile phase and the supernatant $(50 \mu \mathrm{L})$ was injected into the high-performance liquid chromatography system, which comprised a Waters 2487 dual $\lambda$ absorbance detector and a 1525 pump (Waters, Milford, MA). An ODS $3 \mathrm{C}-18$ analytical column (5 $\mu \mathrm{m}$, $250 \times 4.6 \mathrm{~mm}$, Phenomenex, Torrance, CA) was used and the wavelength was set at $227 \mathrm{~nm}$. The flow rate was $1 \mathrm{~mL}$ per minute, with the mobile phase starting from $100 \%$ solvent $A$ (acetonitrile: water $=60: 40 \mathrm{v} / \mathrm{v}$ ) for 10 minutes, then a linear gradient to $100 \%$ solvent $\mathrm{B}$ (acetonitrile) at 12 minutes, and sustained at $100 \%$ solvent B for 20 minutes. The retention time of CLA-PTX was approximately 15 minutes.

\section{Statistical analysis}

Data are presented as the mean \pm standard deviation. One-way analysis of variance was used to determine significant differences among groups, after which post hoc tests with Bonferroni correction were used for comparisons between individual groups. Statistical significance was established at $P<0.05$.

\section{Results \\ Characterization of CLA-PTX microemulsion}

The concentrated CLA-PTX microemulsion was transparent and slightly yellow in color. The concentrations of CLA-PTX, 
CrEL, and Lipoid E 80 in the concentrated microemulsion were 80,95 , and $190 \mathrm{mg} / \mathrm{mL}$, respectively. In addition, the concentrated CLA-PTX microemulsion was stable for at least one month without any precipitation of CLA-PTX. The average droplet size in the concentrated CLA-PTX microemulsion after dilution with 5\% glucose infusion was approximately $176.3 \pm 0.8 \mathrm{~nm}$, with a polydispersity index of $0.294 \pm 0.024$. The average zeta potential of the CLA-PTX microemulsion was $-21.31 \pm 4.61 \mathrm{mV}$, as shown in Table 1 . A typical droplet size and distribution is shown in Figure 2A. TEM was used to examine the morphology of the CLA-PTX microemulsion (Figure 2B) and showed that the CLA-PTX microemulsion droplets were spherical in shape. In addition, TEM imaging showed that the droplet size of the microemulsion was smaller than that in Table 1. This might be due to the effect of sample preparation (staining and drying) for the TEM analysis.

\section{In vitro cytotoxicity}

A C6 glioma cell line was used to investigate the cytotoxicity of the CLA-PTX microemulsion in comparison with free paclitaxel and CLA-PTX solution. The $\mathrm{IC}_{50}$ values are given in Table 2. It can be concluded from Table 2 that the CLAPTX microemulsion had a similar $\mathrm{IC}_{50}$ value to that of the CLA-PTX solution and free $\operatorname{drug}(P>0.05)$.

\section{In vivo antitumor efficacy}

The in vivo antitumor activity of the CLA-PTX microemulsion was investigated in C6 tumor-bearing nude mice. As shown in Figure 3, the CLA-PTX microemulsion markedly inhibited the growth of $\mathrm{C} 6$ tumors $(P<0.01)$. A similar result was observed in the group treated with Taxol $(P<0.01)$. The antitumor activity of the CLA-PTX microemulsion was significantly higher than that of Taxol $(P<0.01)$. The mean tumor sizes at day 21 after implantation in the Taxol and the CLA-PTX microemulsion groups were $1288 \pm 257$ and $857 \pm 175 \mathrm{~mm}^{3}$, respectively, compared with $2449 \pm 286 \mathrm{~mm}^{3}$ in the control group $(P<0.01)$. Corresponding tumor growth inhibition in the Taxol-treated group and in the CLA-PTX microemulsion-treated group was $47.4 \%$ and $65.0 \%$, respectively.

Table I Droplet size, polydispersity index, and zeta potential of CLA-PTX microemulsion $(n=3)$

\begin{tabular}{llll}
\hline & $\begin{array}{l}\text { Droplet size } \\
(\mathbf{n m})\end{array}$ & Polydispersity & $\begin{array}{l}\text { Zeta potential } \\
(\mathbf{m V})\end{array}$ \\
\hline $\begin{array}{l}\text { CLA-PTX } \\
\text { microemulsion }\end{array}$ & $\mathrm{I} 76.3 \pm 0.8$ & $0.294 \pm 0.024$ & $-2 \mathrm{I} .3 \mathrm{I} \pm 4.6 \mathrm{I}$ \\
\hline
\end{tabular}

Abbreviation: CLA-PTX, linoleic acid conjugated with paclitaxel.

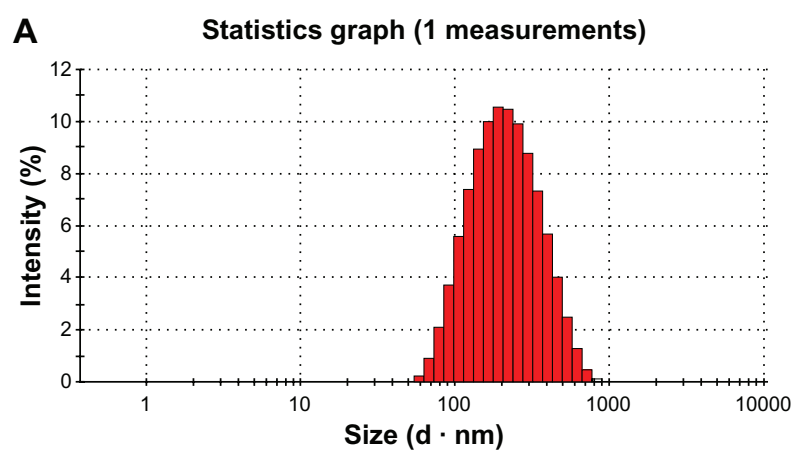

B

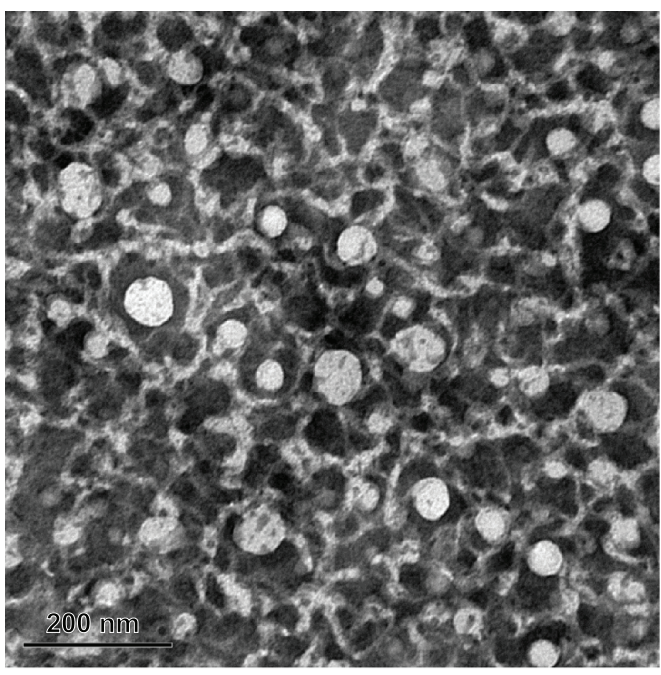

Figure 2 Typical droplet size and distribution of the CLA-PTX microemulsion (A) and transmission electron micrograph of CLA-PTX microemulsion (B).

Note: Bar $200 \mathrm{~nm}$.

Abbreviation: CLA-PTX, linoleic acid conjugated with paclitaxel.

The antitumor effect of the CLA-PTX microemulsion was also compared with that of Taxol by measuring the tumor weight in C6 glioma tumor-bearing rats after cell implantation. As shown in Figure 4, the CLA-PTX microemulsion markedly inhibited growth of the C6 glioma tumors $(P<0.01)$. In contrast, Taxol had no significant inhibitory effect on the growth of C6 glioma tumors at a dose of $5 \mathrm{mg} / \mathrm{kg}$ $(P>0.05)$. The average tumor weight in the groups treated with $5 \%$ glucose infusion, Taxol $5 \mathrm{mg} / \mathrm{kg}$, and CLA-PTX microemulsion $(6.67 \mathrm{mg} / \mathrm{kg})$ at day 20 after C6 glioma cell implantation was 386, 361, and $150 \mathrm{mg}$, respectively. As shown in Table 3, the TWI (\%) value in the group treated with the CLA-PTX microemulsion versus that in the control

Table 2 Cytotoxicity of various CLA-PTX formulations for C6 cells $(n=3)$

\begin{tabular}{ll}
\hline CLA-PTX formulations & IC $_{50}(\mu \mathbf{M})$ \\
\hline Free PTX & $2.11 \pm 1.03$ \\
CLA-PTX solution & $2.47 \pm 1.16$ \\
CLA-PTX microemulsion & $1.61 \pm 0.83$ \\
\hline
\end{tabular}

Abbreviation: CLA-PTX, linoleic acid conjugated with paclitaxel. 


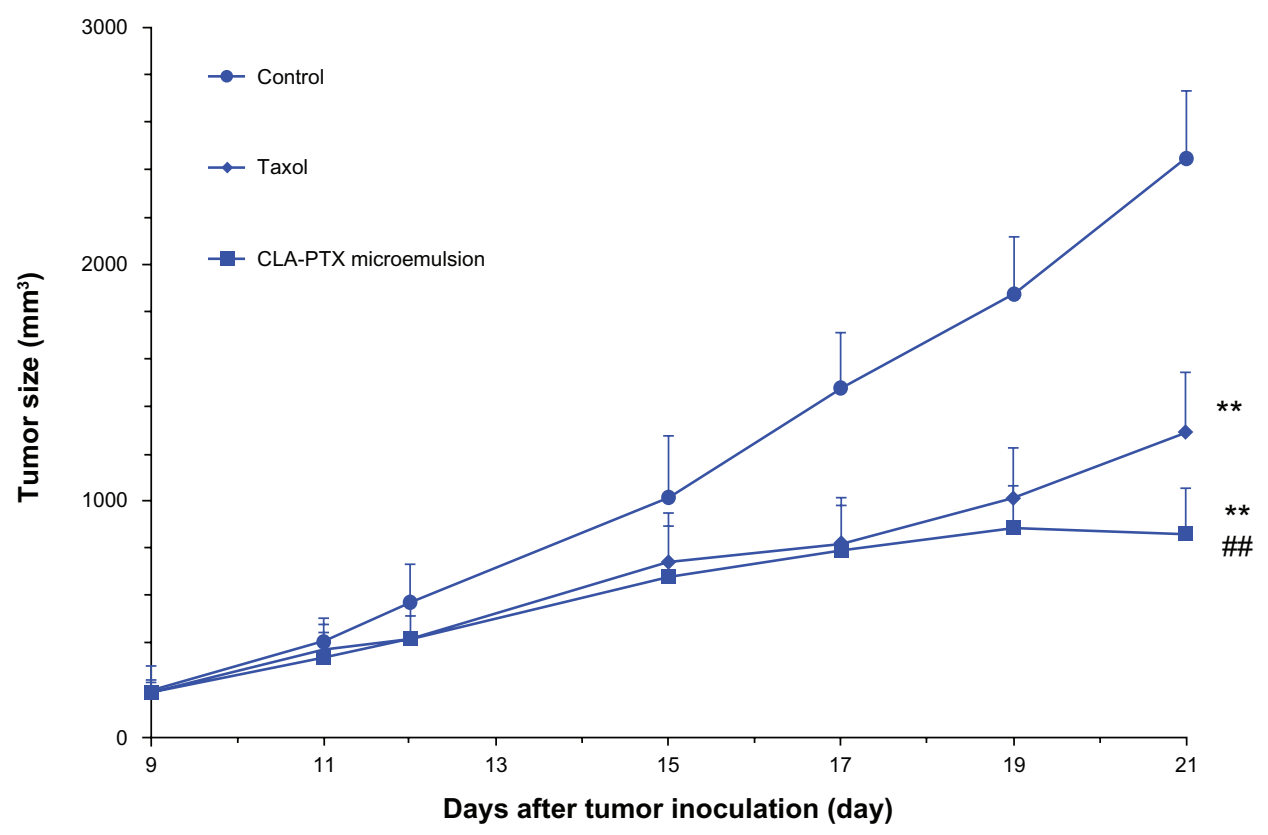

Figure 3 In vivo antitumor activity of CLA-PTX microemulsion in C6 tumor-bearing nude mice.

Notes: Balb/C nude mice were inoculated subcutaneously with $\mathrm{C} 6$ cells and treated with a $5 \%$ glucose infusion, Taxol ${ }^{\circledR}$ ( $15 \mathrm{mg} / \mathrm{kg}$, intravenously, every 3 days for three doses), or CLA-PTX microemulsion $20 \mathrm{mg} / \mathrm{kg}$ (equimolar with $15 \mathrm{mg} / \mathrm{kg}$ of paclitaxel), intravenously every 3 days for three doses, respectively. The control group was given the $5 \%$ glucose infusion. Formulations were given intravenously via the tail vein. Throughout the study, the mice were weighed and tumors were measured with calipers every two days. $* * P<0.01$ versus $5 \%$ glucose infusion as control; $P<0.01$ versus Taxol.

Abbreviation: CLA-PTX, linoleic acid conjugated with paclitaxel.

group and the Taxol treatment group $(5 \mathrm{mg} / \mathrm{kg})$ was about $61.1 \%$ and $58.5 \%$, respectively.

\section{In vivo pharmacokinetics}

The plasma concentration-time profiles of CLA-PTX after intravenous administration of the CLA-PTX formulations were characterized in rats. As shown in Figure 5, the concentration

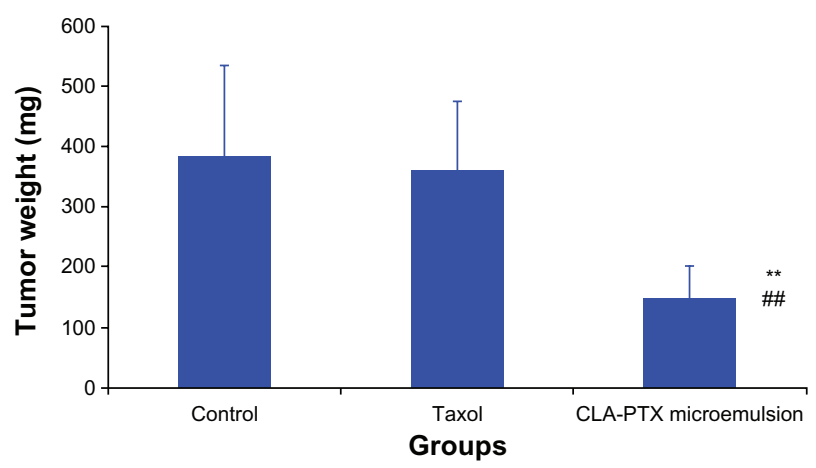

Figure 4 In vivo antitumor activity of CLA-PTX microemulsion in C6 brain tumor-bearing rats.

Notes: Tumor weight is shown at the time of sacrifice, 20 days post-inoculation. Formulations were administered intravenously via the tail vein at days 7,10 , and 13 after tumor inoculation. Animals were sacrificed on day 20 post-tumor inoculation $(n=10)$. Control group, $5 \%$ glucose infusion; Taxol ${ }^{\circledR}$ treatment group, at a dose of $5 \mathrm{mg} / \mathrm{kg}$; CLA-PTX microemulsion treatment group, at a dose of $6.67 \mathrm{mg} / \mathrm{kg}$ (equimolar with $5 \mathrm{mg} / \mathrm{kg}$ of paclitaxel). $* * P<0.01$ versus $5 \%$ glucose infusion as control; $\#>0.0$ l versus Taxol treatment group.

Abbreviation: CLA-PTX, linoleic acid conjugated with paclitaxel. of CLA-PTX in the group treated with the CLA-PTX solution was significantly higher than that in the group treated with the CLA-PTX microemulsion. The main pharmacokinetic parameters of CLA-PTX are summarized in Table 4, and show that the CLA-PTX solution had significantly higher values for $\mathrm{C}_{0.5}, \mathrm{AUC}_{\mathrm{inf}}, \mathrm{t}_{1 / 2}$, and mean residence time $(132.9 \mu \mathrm{M} / \mathrm{mL}$, 2296 hours $\mu \mathrm{M} / \mathrm{mL}, 59.6$ hours, and 36.6 hours, respectively) than did the CLA-PTX microemulsion $(68.5 \mu \mathrm{M} / \mathrm{mL}$, 389 hours $\mu \mathrm{M} / \mathrm{mL}, 24.4$ hours, and 18.9 hours, respectively, $P<0.01$ ), whereas the CLA-PTX microemulsion produced significantly higher values for $\mathrm{V}_{\mathrm{ss}}$ and $\mathrm{Cl}(0.62 \mathrm{~L} / \mathrm{kg}$ and $16.8 \mathrm{~mL} /$ hour $\cdot \mathrm{kg}$, respectively) than did the CLA-PTX solution $(0.22 \mathrm{~L} / \mathrm{kg}$ and $2.26 \mathrm{~mL} /$ hour $\cdot \mathrm{kg}$, respectively, $P<0.01)$.

\section{Acute toxicity}

Figure 6 shows the acute toxicity of the intravenous CLAPTX solution and CLA-PTX microemulsion in mice, as

Table 3 Tumor weight inhibition (\%) of CLA-PTX microemulsion against control and Taxol ${ }^{\circledR}$

\begin{tabular}{llll}
\hline Groups & Dose & $\begin{array}{l}\text { TWI (\%) } \\
\text { against control }\end{array}$ & $\begin{array}{l}\text { TWI (\%) } \\
\text { against taxol }\end{array}$ \\
\hline $\begin{array}{l}\text { CLA-PTX } \\
\text { microemulsion }\end{array}$ & $6.67 \mathrm{mg} / \mathrm{kg}$ & $61.1 \pm 13.5$ & $58.5 \pm 14.4$ \\
\hline
\end{tabular}

Abbreviations: CLA-PTX, linoleic acid conjugated with paclitaxel; TWI, tumor weight inhibition. 


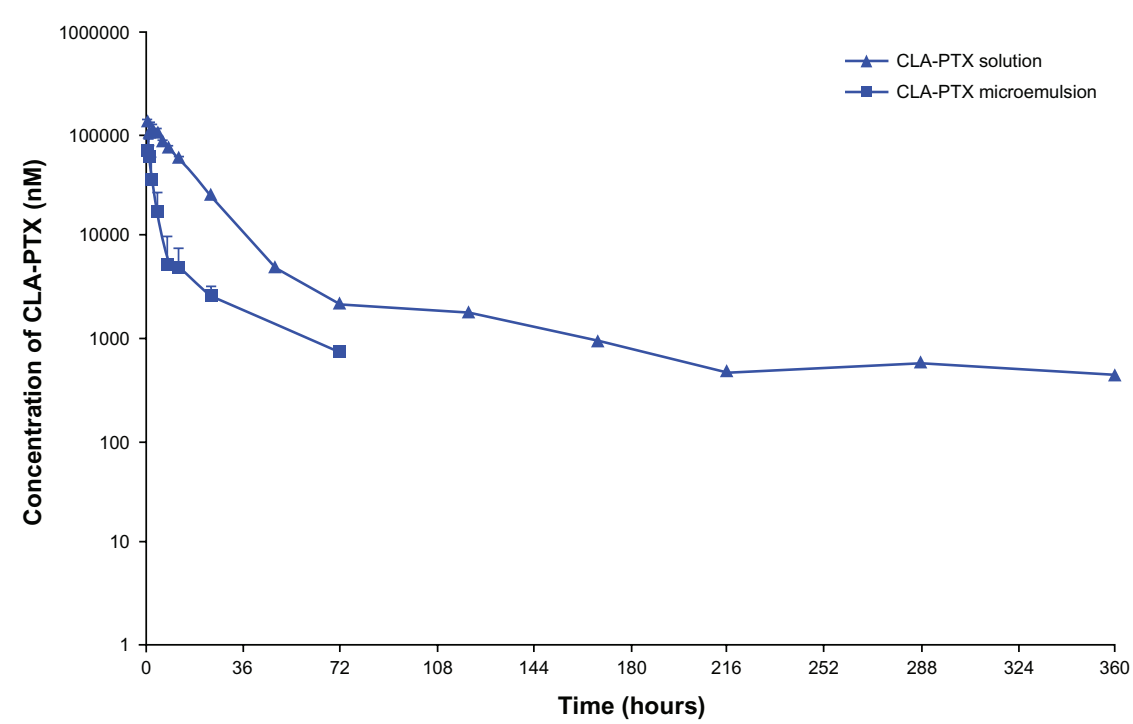

Figure 5 Plasma concentration-time profiles of CLA-PTX after intravenous administration of CLA-PTX solution or CLA-PTX microemulsion at 6.67 mg/kg CLA-PTX in Sprague-Dawley rats.

Notes: Mean \pm standard deviation, $n=5$.

Abbreviation: CLA-PTX, linoleic acid conjugated with paclitaxel.

determined by the median lethal dose $\left(\mathrm{LD}_{50}\right)$. No mortality or significant toxic symptoms were observed in mice treated with up to $200 \mathrm{mg} / \mathrm{kg}$ of the CAL-PTX microemulsion. Therefore, the $\mathrm{LD}_{50}$ of the CLA-PTX microemulsion is expected to be higher than $200 \mathrm{mg} / \mathrm{kg}$. In contrast with the CLA-PTX solution, there were 3, 7, and 10 deaths within 4 hours of administration of the CLA-PTX solution at doses of $95.2,113.4$, and $135 \mathrm{mg} / \mathrm{kg}$, respectively. The $\mathrm{LD}_{50}$ of the CLA-PTX solution administere by the intravenous route to mice was $103.9 \mathrm{mg} / \mathrm{kg}$. The $95 \%$ confidence limits were found to lie within the range of $96.1-112.3 \mathrm{mg} / \mathrm{kg}$.

\section{Discussion}

In the present study, we designed and prepared a novel CLA-PTX microemulsion. The droplet size and TEM results

Table 4 Main pharmacokinetic parameters of CLA-PTX after intravenous administration of CLA-PTX solution or CLA-PTX microemulsion at $6.67 \mathrm{mg} / \mathrm{kg}$ of CLA-PTX in Sprague-Dawley rats $(\mathrm{n}=5)$

\begin{tabular}{llcc}
\hline Parameters & Units & $\begin{array}{l}\text { CLA-PTX } \\
\text { solution }\end{array}$ & $\begin{array}{l}\text { CLA-PTX } \\
\text { microemulsion }\end{array}$ \\
\hline $\mathrm{C}_{0.5}$ & $\mu \mathrm{M}$ & $132.9 \pm 7.0$ & $68.5 \pm 23.8^{* * *}$ \\
$\mathrm{AUC}_{\text {inf }}$ & Hours* $\mu \mathrm{M}$ & $2296 \pm \mathrm{I} 28$ & $389 \pm 148^{* *}$ \\
$\mathrm{t}_{1 / 2}$ & Hours & $59.6 \pm 25.3$ & $24.4 \pm 5.6 * *$ \\
$\mathrm{MRT}$ & Hours & $36.6 \pm 2.5$ & $18.9 \pm 4.4^{* *}$ \\
$\mathrm{~V}_{\mathrm{ss}}$ & $\mathrm{L} / \mathrm{kg}$ & $0.218 \pm 0.084$ & $0.619 \pm 0.28 \mathrm{I} * *$ \\
$\mathrm{Cl}$ & $\mathrm{mL} / \mathrm{hour} / \mathrm{kg}$ & $2.68 \pm 0.669$ & $16.8 \pm 4.7^{* *}$ \\
\hline
\end{tabular}

Note: ${ }^{* *} P<0.0$ I versus CLA-PTX solution treatment group.

Abbreviations: AUC, area under the concentration-time curve; CLA-PTX, linoleic acid conjugated with paclitaxel; MRT, mean residence time. show that the concentrated CLA-PTX microemulsion would self-emulsify to form nanosized microemulsion droplets (Figure 1 and Table 1). The antitumor activity of the CLAPTX microemulsion for the treatment of brain tumors was confirmed in our in vivo $\mathrm{C} 6$ glioma tumor-bearing nude mice as well as in a rat model (Figures 3 and 4). In contrast, Taxol had almost no significant antitumor effect on inhibition of tumor growth in C6 glioma tumor-bearing rats (Figure 4), although Taxol markedly inhibited the growth of C6 tumors in the C6 glioma tumor-bearing nude mice (Figure 3). One possible reason for this may be that the blood-brain barrier, which is a formidable barrier to many agents directed against malignant cells within the brain, ${ }^{22}$ prevents paclitaxel reaching brain tissue. Our previous study showed that CLA-PTX, unlike paclitaxel, could distribute and maintain high levels in brain tissue, indicating its potential ability to cross the blood-brain barrier. ${ }^{9}$ Therefore, we suggested that CLA-PTX in the microemulsion could cross the blood-brain barrier and have antitumor activity in the brain. According to our previous results for the antitumor activity of CLA-PTX solution in C6 glioma tumor-bearing rats (average tumor weight $126.9 \pm 95.1 \mathrm{mg}),{ }^{9}$ we suggest that the antitumor activity of the CLA-PTX microemulsion (average tumor weight $149.9 \pm 52.0 \mathrm{mg}$ ) is similar to that of CLA-PTX solution in C6 glioma tumor-bearing rats $(P>0.05)$.

There are many reported strategies for drug targeting to brain tumors, ${ }^{23}$ such as modified nanoparticles or solid lipid nanoparticles. ${ }^{24-27}$ It has been also reported that intranasal administration of micro/nanoemulsions could have a 


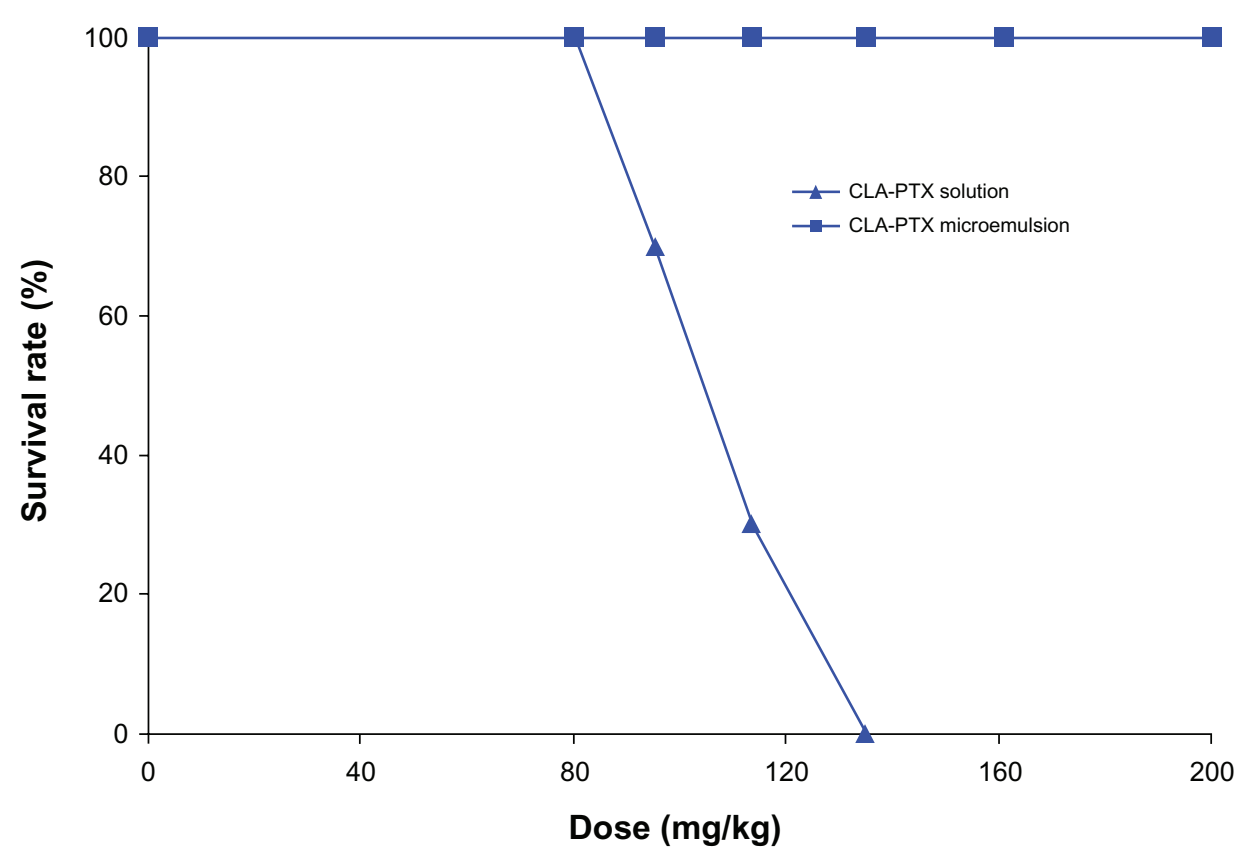

Figure 6 Acute toxicity of CLA-PTX microemulsion (- - -) and CLA-PTX solution (- $\mathbf{\Delta}-)$ administered via the intravenous route. Note: $\mathrm{n}=10$ per dose.

Abbreviation: CLA-PTX, linoleic acid conjugated with paclitaxel.

brain-targeting effect. ${ }^{28-37}$ In the present study, we confirmed that a CLA-PTX microemulsion administered intravenously could also produce antitumor activity in brain tissue.

The plasma concentration of CLA-PTX was determined after a single intravenous injection of CLA-PTX solution or CLA-PTX microemulsion. As shown in Figure 5 and Table 4, CLA-PTX in the solution showed a much longer circulation time and a higher drug plasma concentration than did CLA-PTX in the microemulsion formulation $(P<0.01)$. The $\mathrm{C}_{0.5}, \mathrm{AUC}_{\text {inf }}, \mathrm{t}_{1 / 2}$, and mean residence time of the drug in plasma for the group receiving the CLA-PTX solution were increased by 1.9 -fold, 5.9-fold, 2.4-fold, and 1.9-fold compared with the group receiving the CLA-PTX microemulsion $(P<0.01)$. Although the higher plasma concentration and prolonged plasma circulation are responsible for the increased therapeutic efficacy of the CLA-PTX microemulsion, the present study shows that the antitumor activity of the CLA-PTX microemulsion was similar to that of the CLA-PTX solution in $\mathrm{C} 6$ glioma tumor-bearing rats. We suggest that this is due to the enhanced permeability and retention effect via a passive targeting mechanism, which is the principal physiology-based mechanism for accumulation of larger molecules and small particles in tumor tissue. ${ }^{38}$ Therefore, these CLA-PTX droplets in the microemulsion would be removed from the circulation and accumulate in tumor tissues to produce an antitumor activity.
The solvent used in the CLA-PTX solution is a mixture of CrEL and dehydrated ethanol $(1: 1, \mathrm{v} / \mathrm{v})$. The concentration of CLA-PTX in the CLA-PTX solution was $15 \mathrm{mg} / \mathrm{mL}$, containing the CrEL at $527 \mathrm{mg} / \mathrm{mL}$ and dehydrated ethanol at $396 \mathrm{mg} / \mathrm{mL}$. In contrast, the concentration of CLA-PTX in the concentrated CLA-PTX microemulsion was $80 \mathrm{mg} / \mathrm{mL}$, containing only $95 \mathrm{mg} / \mathrm{mL}$ CrEL. The ratio of CLA-PTX to CrEL in the CAL-PTX microemulsion and CLA-PTX solution is 35.1 and 1.2, respectively, indicating that the CrEL in the CLA-PTX microemulsion is significantly reduced. It has been reported that treatment with CrEL alone produces asthenia, tachypnea, convulsions, and ultimately death in dogs and mice. ${ }^{39,40}$ In the present acute toxicity study, the $\mathrm{LD}_{50}$ of the CLA-PTX solution was calculated to be $103.9 \mathrm{mg} / \mathrm{kg}$. According to the components of the CLA-PTX solution, when $103.9 \mathrm{mg} / \mathrm{kg}$ CLA-PTX was injected into mice, the dose of $\mathrm{CrEL}$ was $3584 \mathrm{mg} / \mathrm{kg}$. In contrast, the calculated CrEL in the CLA-PTX microemulsion at the given dose of $200 \mathrm{mg} / \mathrm{kg}$ for mice was only $235 \mathrm{mg} / \mathrm{kg}$. Therefore, it may be concluded that the acute toxicity of CLA-PTX solution is primarily due to the toxicity of CrEL. However, the cause of CrEL-related acute mortality was not investigated in this study. Considering the $\mathrm{LD}_{50}$ results, we suggest that the CLA-PTX microemulsion is safer than the CLA-PTX solution, and a high dose of CLA-PTX microemulsion can be used for future therapeutic studies due to the fact that the concentration of CrEL in this microemulsion is significantly reduced. 


\section{Conclusion}

In summary, we have designed and prepared a novel CLA-PTX microemulsion. The droplet size and TEM results show that the concentrated CLA-PTX microemulsion self-emulsifies to form nanosized microemulsion droplets. The antitumor activity of the CLA-PTX microemulsion in the treatment of brain tumors was confirmed in our in vivo $\mathrm{C} 6$ glioma tumor-bearing nude mouse model as well as in a rat model. In contrast, Taxol had almost no significant antitumor effect in C6 glioma tumorbearing rats, but could markedly inhibit growth of tumors in C6 glioma tumor-bearing nude mice. Although the CLA-PTX in the CLA-PTX solution showed a much longer circulation time and higher drug plasma concentrations compared with the CLA-PTX microemulsion, the antitumor activity of the CLA-PTX microemulsion was similar to that of the CLAPTX solution. Due to the reduction in CrEL, the CLA-PTX microemulsion is safer than CLA-PTX solution, and a high dose of CLA-PTX microemulsion could be used for future therapeutic studies.

\section{Acknowledgments}

The authors gratefully acknowledge the financial support of the National Natural Science Foundation of China (81172992), the National Basic Research Program of China (973 Program 2009CB930300, 2013CB932501) and the Innovation Team of the Ministry of Education (BMU20110263).

\section{Disclosure}

The authors report no conflicts of interest in this work.

\section{References}

1. De la Torre A, Debiton E, Durand D, et al. Conjugated linoleic acid isomers and their conjugated derivatives inhibit growth of human cancer cell lines. Anticancer Res. 2005;25:3943-3439.

2. Stachowska E. Conjugated dienes of linoleic acid and tumorigenesis. Ann Acad Med Stetin. 2008;54:122-125. Polish.

3. Beppu F, Hosokawa M, Tanaka L, Kohno H, Tanaka T, Miyashita K. Potent inhibitory effect of trans9, trans 11 isomer of conjugated linoleic acid on the growth of human colon cancer cells. J Nutr Biochem. 2006;17: 830-836.

4. Cunningham DC, Harrison LY, Shultz TD. Proliferative responses of normal human mammary and MCF-7 breast cancer cells to linoleic acid, conjugated linoleic acid and eicosanoid synthesis inhibitors in culture. Anticancer Res. 1997;17:197-203.

5. Maggiora M, Bologna M, Cerù MP, et al. An overview of the effect of linoleic and conjugated-linoleic acids on the growth of several human tumor cell lines. Int J Cancer. 2004;112:909-919.

6. Tanmahasamut P, Liu J, Hendry LB, Sidell N. Conjugated linoleic acid blocks estrogen signaling in human breast cancer cells. J Nutr. 2004;134: 674-680.

7. Menéndez JA, del Mar Barbacid M, Montero S, et al. Effects of gammalinolenic acid and oleic acid on paclitaxel cytotoxicity in human breast cancer cells. Eur J Cancer. 2001;37:402-413.
8. Fite A, Goua M, Wahle KW, Schofield AC, Hutcheon AW, Heys SD Potentiation of the anti-tumour effect of docetaxel by conjugated linoleic acids (CLAs) in breast cancer cells in vitro. Prostaglandins Leukot Essent Fatty Acids. 2007;77:87-96.

9. Ke XY, Zhao BJ, Zhao X, et al. The therapeutic efficacy of conjugated linoleic acid - paclitaxel on glioma in the rat. Biomaterials. 2010;31: 5855-5864.

10. Singh A, Worku ZA, Van den Mooter G. Oral formulation strategies to improve solubility of poorly water-soluble drugs. Expert Opin Drug Deliv. 2011;8:1361-1378.

11. Shi Y, Porter W, Merdan T, Li LC. Recent advances in intravenous delivery of poorly water-soluble compounds. Expert Opin Drug Deliv. 2009;6:1261-1282.

12. Fahr A, Liu X. Drug delivery strategies for poorly water-soluble drugs. Expert Opin Drug Deliv. 2007;4:403-416.

13. Bagwe RP, Kanicky JR, Palla BJ, Patanjali PK, Shah DO. Improved drug delivery using microemulsions: rationale, recent progress, and new horizons. Crit Rev Ther Drug Carrier Syst. 2001;18:77-140.

14. Talegaonkar S, Azeem A, Ahmad FJ, Khar RK, Pathan SA, Khan ZI. Microemulsions: a novel approach to enhanced drug delivery. Recent Pat Drug Deliv Formul. 2008;2:238-257.

15. He CX, He ZG, Gao JQ. Microemulsions as drug delivery systems to improve the solubility and the bioavailability of poorly water-soluble drugs. Expert Opin Drug Deliv. 2010;7:445-460.

16. Shen Q, Li X, Yuan D, Jia W. Enhanced oral bioavailability of daidzein by self-microemulsifying drug delivery system. Chem Pharm Bull (Tokyo). 2010;58:639-643.

17. Yin YM, Cui FD, Mu CF, et al. Docetaxel microemulsion for enhanced oral bioavailability: preparation and in vitro and in vivo evaluation. J Control Release. 2009;140:86-94.

18. Wang Y, Wu KC, Zhao BX, et al. A novel paclitaxel microemulsion containing a reduced amount of Cremophor EL: pharmacokinetics, biodistribution, and in vivo antitumor efficacy and safety. $J$ Biomed Biotechnol. 2011;2011:854872.

19. von Eckardstein KL, Patt S, Kratzel C, Kiwit JC, Reszka R. Local chemotherapy of F98 rat glioblastoma with paclitaxel and carboplatin embedded in liquid crystalline cubic phases. J Neurooncol. 2005;72: 209-215.

20. Petrangolini G, Supino R, Pratesi G, et al. Effect of a novel vacuolar$\mathrm{H}+$-ATPase inhibitor on cell and tumor response to camptothecins. J Pharmacol Exp Ther. 2006;318:939-946.

21. Liu X, Sun J, Chen X, et al. Pharmacokinetics, tissue distribution and anti-tumour efficacy of paclitaxel delivered by polyvinylpyrrolidone solid dispersion. J Pharm Pharmacol. 2012;64:775-782.

22. Puduvalli VK, Sawaya R. Antiangiogenesis - therapeutic strategies and clinical implications for brain tumors. J Neurooncol. 2000;50: 189-200.

23. Pardridge WM. Drug targeting to the brain. Pharm Res. 2007;24: 1733-1744.

24. Wagner S, Zensi A, Wien SL, et al. Uptake mechanism of ApoEmodified nanoparticles on brain capillary endothelial cells as a bloodbrain barrier model. PLoS One. 2012;7:e32568.

24. Xin H, Sha X, Jiang X, Zhang W, Chen L, Fang X. Anti-glioblastoma efficacy and safety of paclitaxel-loading Angiopep-conjugated dual targeting PEG-PCL nanoparticles. Biomaterials. 2012;33: 8167-8176.

25. Gao H, Qian J, Cao S, et al. Precise glioma targeting of and penetration by aptamer and peptide dual-functioned nanoparticles. Biomaterials 2012;33:5115-5123.

26. Bondì ML, Di Gesù R, Craparo EF. Lipid nanoparticles for drug targeting to the brain. Methods Enzymol. 2012;508:229-251.

27. Biddlestone-Thorpe L, Marchi N, Guo K, et al. Nanomaterial-mediated CNS delivery of diagnostic and therapeutic agents. Adv Drug Deliv Rev. 2012;64:605-613.

28. Zhang Q, Jiang X, Jiang W, Lu W, Su L, Shi Z. Preparation of nimodipine-loaded microemulsion for intranasal delivery and evaluation on the targeting efficiency to the brain. Int J Pharm. 2004;275:85-96. 
29. Piao HM, Balakrishnan $\mathrm{P}$, Cho HJ, et al. Preparation and evaluation of fexofenadine microemulsions for intranasal delivery. Int J Pharm. 2010;395:309-316.

30. Bondì ML, Craparo EF, Giammona G, Drago F. Brain-targeted solid lipid nanoparticles containing riluzole: preparation, characterization and biodistribution. Nanomedicine (Lond). 2010;5:25-32.

31. Vyas TK, Babbar AK, Sharma RK, Singh S, Misra A. Intranasal mucoadhesive microemulsions of clonazepam: preliminary studies on brain targeting. J Pharm Sci. 2006;95:570-580.

32. Kumar M, Misra A, Babbar AK, Mishra AK, Mishra P, Pathak K. Intranasal nanoemulsion based brain targeting drug delivery system of risperidone. Int J Pharm. 2008;358:285-291.

33. Gaoe H, Pang Z, Pan S, et al. Anti-glioma effect and safety of docetaxelloaded nanoemulsion. Arch Pharm Res. 2012;35:333-341.

34. Ganta S, Deshpande D, Korde A, Amiji M. A review of multifunctional nanoemulsion systems to overcome oral and CNS drug delivery barriers. Mol Membr Biol. 2010;27:260-273.
35. Kumar M, Misra A, Mishra AK, Mishra P, Pathak K. Mucoadhesive nanoemulsion-based intranasal drug delivery system of olanzapine for brain targeting. J Drug Target. 2008;16:806-814.

36. Desai A, Vyas T, Amiji M. Cytotoxicity and apoptosis enhancement in brain tumor cells upon coadministration of paclitaxel and ceramide in nanoemulsion formulations. J Pharm Sci. 2008;97:2745-2756.

37. Vyas TK, Shahiwala A, Amiji MM. Improved oral bioavailability and brain transport of Saquinavir upon administration in novel nanoemulsion formulations. Int J Pharm. 2008;347:93-101.

38. Torchilin V. Tumor delivery of macromolecular drugs based on the EPR effect. Adv Drug Deliv Rev. 2011;63:131-135.

39. Rowinsky EK, Cazenave LA, Donehower RC. Taxol: a novel investigational antimicrotubule agent. J Natl Cancer Inst. 1990;82: 1247-1259.

40. Park JH, Chi SC, Lee WS, et al. Toxicity studies of Cremophor-free paclitaxel solid dispersion formulated by a supercritical antisolvent process. Arch Pharm Res. 2009;32:139-148.
International Journal of Nanomedicine

\section{Publish your work in this journal}

The International Journal of Nanomedicine is an international, peerreviewed journal focusing on the application of nanotechnology in diagnostics, therapeutics, and drug delivery systems throughout the biomedical field. This journal is indexed on PubMed Central, MedLine, CAS, SciSearch $\AA$, Current Contents ${ }^{\circledR} /$ Clinical Medicine,

\section{Dovepress}

Journal Citation Reports/Science Edition, EMBase, Scopus and the Elsevier Bibliographic databases. The manuscript management system is completely online and includes a very quick and fair peer-review system, which is all easy to use. Visit http://www.dovepress.com/ testimonials.php to read real quotes from published authors. 